\title{
Accurate Circuit Model for Steady-State and Dynamic Performance of Lead-Acid AGM Batteries
}

\author{
W. Peng, Student Member, IEEE, and Y. Baghzouz, Senior Member, IEEE
}

\begin{abstract}
Electrochemical batteries are rapidly gaining widespread application in transportation systems as well as in the electric utility sector, and accurate battery models are need during the design stage of such systems to forecast future performance. This paper proposes a simple and yet accurate model of a sealed AGM battery. The model takes into account the nonlinear characteristics of the discharge curves, and its parameters are derived by using the manufacturer's data sheet in addition to a simple laboratory test on a $12 \mathrm{~V}, 89$ Ah battery. Comparison between the measured and calculated responses to a number of different discharge profiles shows a comfortable degree of accuracy of the proposed battery model.
\end{abstract}

Index Terms-Lead Acid Battery, Battery Charge and Discharge Characteristics, Steady-State and Dynamic Performance, Modeling and Simulation.

\section{INTRODUCTION}

$\mathrm{E}_{\mathrm{b}}^{\mathrm{s}}$ LECTRIC energy storage in electrochemical batteries is becoming an importance subject in nowadays. This is due to widespread needs in mobile applications (e.g., pure-electric and hybrid-electric vehicles) an in stationary power storage (e.g., electric utility peak shaving and renewable energy smoothing) [1]-[3]. Among the many types of rechargeable batteries available commercially, the Absorbed-Glass-Mat (AGM) battery a type of Valve-Regulated-Lead-Acid (VRLA) battery is widely popular in renewable energy storage systems due to its high performance and maintenance-free requirement [4]. A circuit model that depicts the performance of this particular battery is valuable for simulation studies.

Circuit modeling of lead-acid batteries has been investigated by a number of researchers over the past several decades. The various models proposed in the literature vary widely in complexity and accuracy, and a good overview can be found in Refs. [5] - [12]. This paper derives an accurate and yet relatively simple circuit model for lead-acid AGM batteries. The model consists of three elements: a voltage source (which can be substituted for large capacitance) that is dependent on the rate of discharge and State Of Charge, a series resistance that depends on the rate of discharge, and a shunt capacitance to account of the dynamic response. The static model parameters are derived from the discharge curves supplied by the manufacturer, while the dynamic components are derived from laboratory test data. The model is tested under different types of load current profile and is found to provide sufficiently accurate results.

\section{Derivation of Static Battery Model From MANUFACTURER DATA}

The AGM valve-regulated battery selected in this study is supplied by Sun Xtender, a division of the Concorde Battery Corp. More specifically, the model tested (PVX-890T) is rated at a nominal voltage of $12 \mathrm{~V}$ and capacity of $89 \mathrm{Ah}$ at the 24hour rate. The discharge curves of this product line are found in the manufacturer's technical manual [13], and are shown in Fig. 1 below for convenience. This figure displays the battery terminal voltage $\mathrm{Vb}$ as a function of the Depth-Of-Discharge (DOD) at different discharge rates. Some manufacturers choose the State-Of-Charge (SOC) instead of DOD as a horizontal axis, and these measures are related by

$$
S O C=1-D O D
$$

Furthermore, given an initial battery state-of-charge SOCo, and after the battery supplies a constant current I for some time $t$ (in hours), the new SOC is computed by

$$
S O C=S O C_{0}-\frac{I t}{N C}
$$

Where $N C$ is the battery nominal capacity in amp-hours.

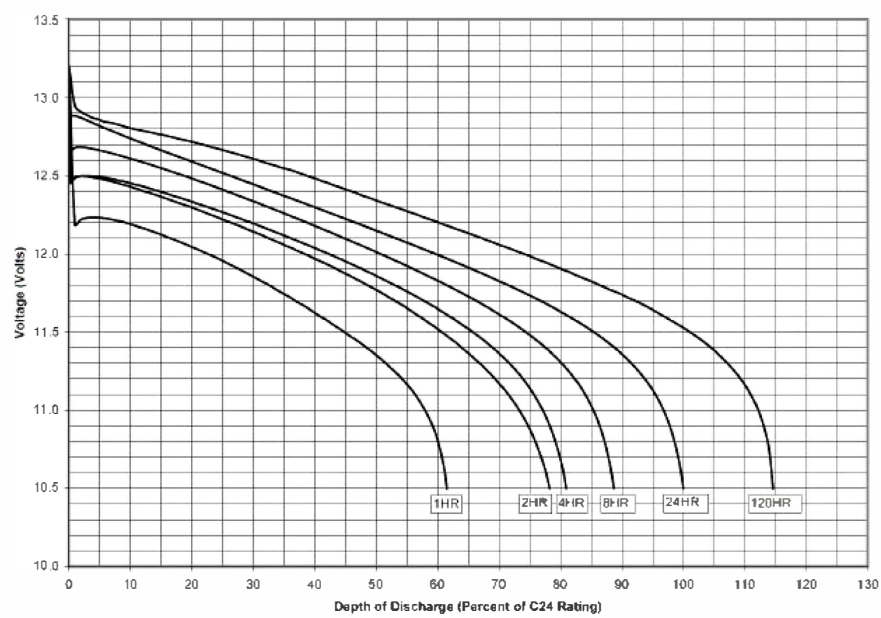

Fig. 1. Manufacturer's Discharge Curves at Various Rates $\left(\mathrm{T}=25^{\circ} \mathrm{C}\right)[13]$.

A common steady-state circuit for representing a battery consists of the venin equivalent which is made up of a voltage source in series with a resistance. But due to the non-linear characteristics of the curves shown in Fig. 1, both circuit parameters are dependent variables. Hence, the battery is more accurately represented by a voltage source $V_{s}(I, S O C)$ which depends on the battery current and state-of-charge, in series with a variable resistance $R_{s(I)}$ which depends on the battery current. Such a circuit is shown in Fig.2 below. The battery 
terminal voltage $\mathrm{Vb}$ is related to $\mathrm{Vs}$ and $\mathrm{Rs}$ by

$$
V_{b}=V_{s(I, S O C)}-I R_{S(I)}
$$

Where $I$ is the current supplied by the battery to the electrical load.

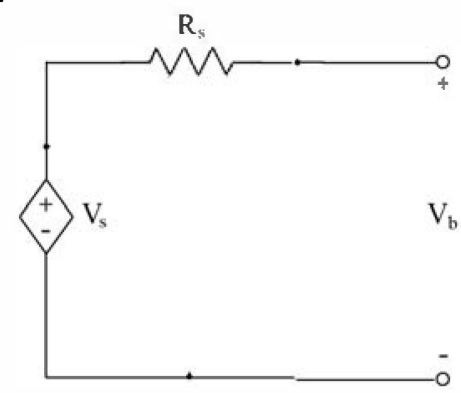

Fig. 2. Steady-State Battery Equivalent Circuit.

In Fig. 2, the dependent voltage source is often replaced by a capacitor $C_{s}$ which depends on both $I$ and $S O C$. In such a case, the internal voltage $V_{s}$ at any given time $t$ can be expressed by

$$
V_{s}=V_{s, o}-\frac{I t}{C_{s(I, S O C)}}
$$

Where $V_{s, o}$ is the initial internal voltage. Substituting (4) into (3) yields the battery terminal voltage:

$$
V_{b}=V_{s, o}-\frac{I t}{C_{s(I, S O C)}}-I R_{s(I)}
$$

The circuit variables that best fit the curves in Fig. 1 are derived by using curve fitting functions that are selected after noting (a) the slope of the linear region increases in a nonlinear fashion with the discharge rate, and (b) the voltage drops exponentially with the DOD after dropping below some specific values. The functions that best fit the discharge curves are found to be as follows:

$$
R_{s(I)}=a_{1} I^{-a_{2}}
$$

and

Herein

$$
C_{s(I, D O D)}=\frac{N C}{a_{3} f(I)+\frac{f(I)}{a_{4} f(I)(D O D)+a_{5}}}
$$

$$
f(I)=a_{6}+a_{7} I
$$

and the constants $a_{0}, \ldots, a_{7}$ are found to equal to the following values: $a_{1}=0.107, a_{2}=0.465, a_{3}=-1.19, a_{4}=13.95, a_{5}=$ 14.78, $a_{6}=0.95$, and $a_{7}=0.012$.

Fig. 3(a) shows how the resistance $R_{s}$ varies with the battery current, while Fig. 3(b) displays the variation of the battery equivalent capacitance $C_{s}$ with current and depth-ofdischarge. Finally, Fig. 4 shows the resulting battery terminal voltage as a function of DOD for different discharge rates. With the exception of the temporary voltage dips that occur at the beginning of the discharge cycle, these curves match very closely with the manufacturer data in Fig. 1. Hence, the steady-state circuit of Fig. 2 with the dependent parameters specified in (6)-(8) can be considered as a satisfactory steadystate model for the specific battery under study.

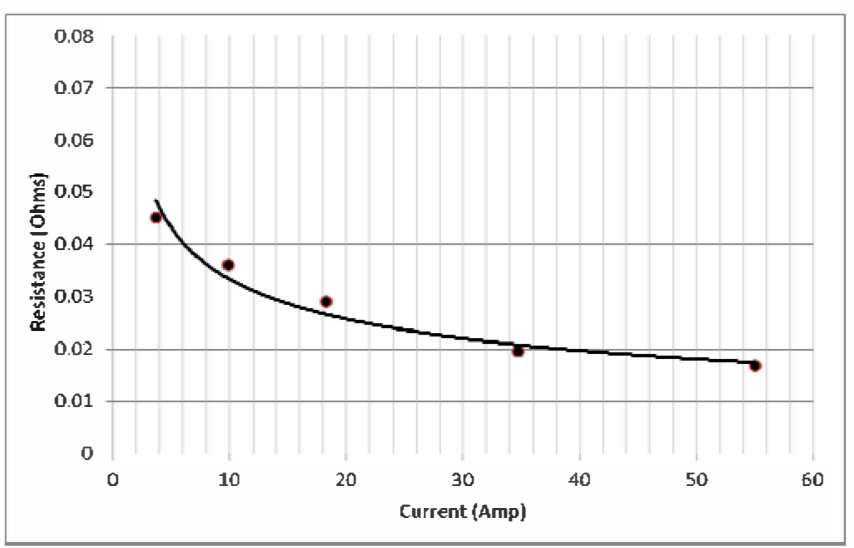

(a)

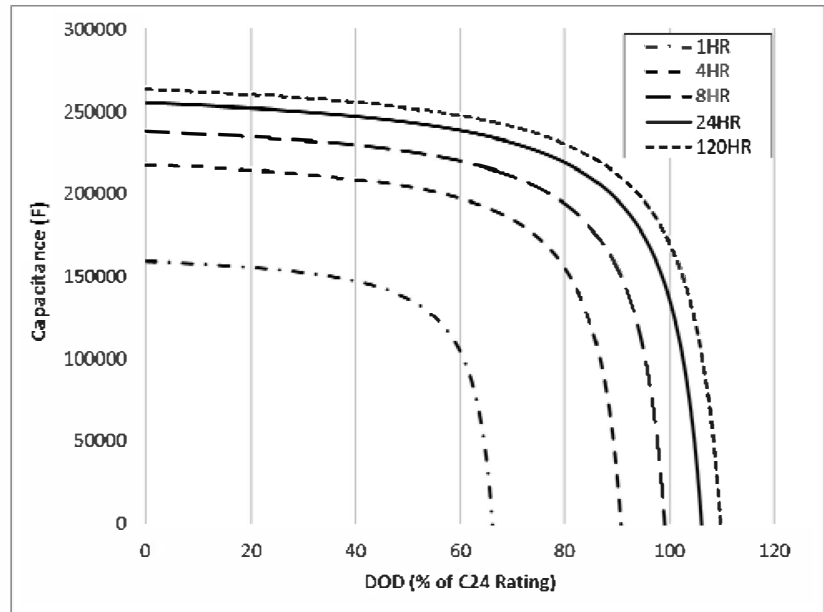

(b)

Fig. 3. Equivalent Circuit Parameters, (a) Resistance, and (b) Capacitance.

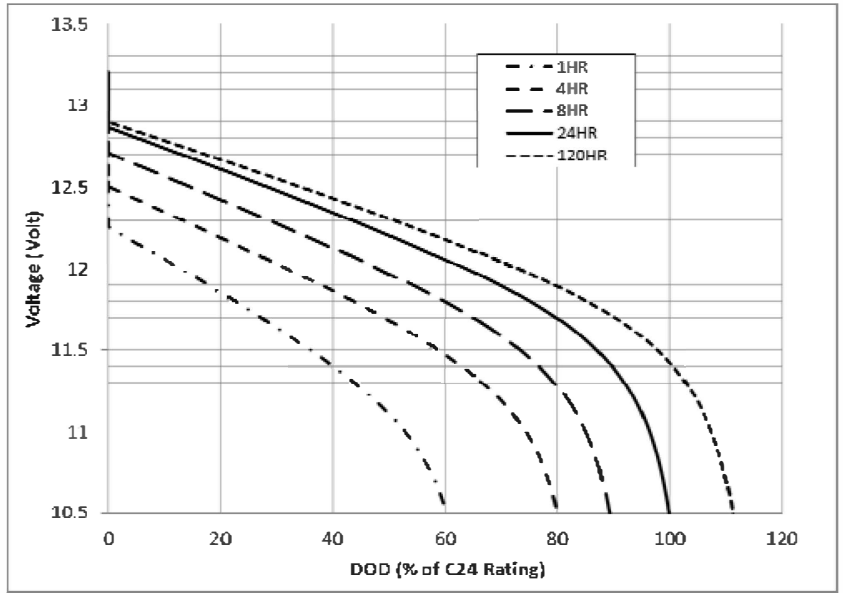

Fig. 4. Calculated Discharge Curves at Different Rates. 


\section{Static BAtTERy MODEL VAlidation}

To validate the equivalent circuit derived in the previous section, a laboratory test was conducted on a battery described earlier. First, the equipment used in the test bench is briefly described. This is followed by a description of the battery charging to assure $100 \%$ initial SOC. Then the battery terminal voltage under different discharge rates is measured and compared to that predicted by the model.

\section{A. Description of Test Bench}

This test bench system consists of the 12V, 89Ah AGM battery under study, a 3-stage battery charger, an electronic load bank, a data logger, and a computer. A schematic diagram is shown in Fig. 5. In this experiment, the discharging current is limited to $25 \mathrm{~A}$ since the electronic load is rated at $300 \mathrm{~W}$.

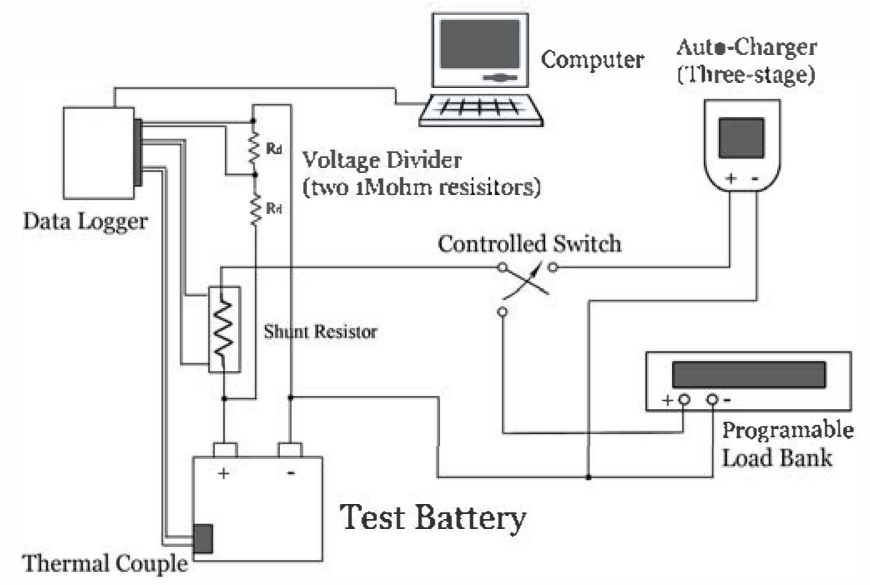

Fig. 5. Schematic Diagram of Test System.

The data logger measures and records the battery current, battery voltage, and battery temperature. A precision-type shunt resistor $R_{g}(=1 \mathrm{~m} \Omega)$ is placed in series to record the battery current by measuring the voltage across its terminals, i.e., a reading of $1 \mathrm{mV}$ corresponds to a current flow of 1 Amp. A simple voltage divider using two equally-sized resistors $R_{s h}$ is used to measure the voltage battery terminal voltage, since the data logger voltage reading is limited to 10 $\mathrm{V}$. when taking the internal resistance of the data logger $R_{d l}$ into account, the recorded voltage $V_{d l}$ is related to the battery voltage $V_{b}$ by

$$
V_{d l}=\frac{R_{s h} R_{d l} /\left(R_{s h}+R_{d l}\right)}{R_{s h}+R_{s h} R_{d l} /\left(R_{s h}+R_{d l}\right)} V_{b}
$$

With $R_{d}=1 \mathrm{M} \Omega$ and $R_{d l} \approx 125 \mathrm{k} \Omega, V_{d l}=0.1 V_{b}$. Hence, the value measured by the data logger is $1 / 10^{\text {th }}$ of the battery voltage. The battery casing temperature is measured by means of a thermocouple.

\section{B. Battery Charging}

Prior to each discharge test, the battery is charged to $100 \%$ SOC by means of a battery charger that uses the three-stage charging scheme the most common way to charge lead-acid batteries. This scheme includes bulk charging (constant current), absorbed charging (constant voltage) and float charging (small constant current to maintain the battery fully charged). The reason of switching to constant voltage is to keep the battery voltage stay below the gassing voltage.

Fig. 6 shows the measured voltage and current profiles during one of the battery charging cycles. Note that bulk charging end when the voltage reaches $14.25 \mathrm{~V}$, and absorbed charging ends when the current drops below $1 \mathrm{~A}$. In here, it took less than 30 minutes for the battery to get fully charged due to the fact that the battery was initially under a high SOC.

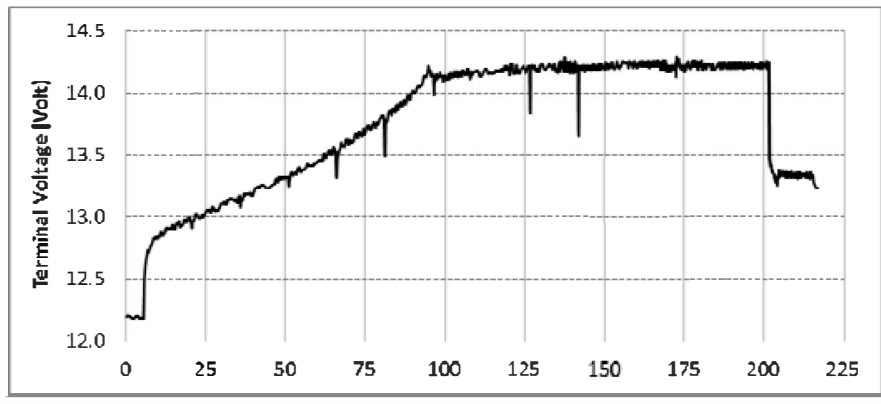

(a)

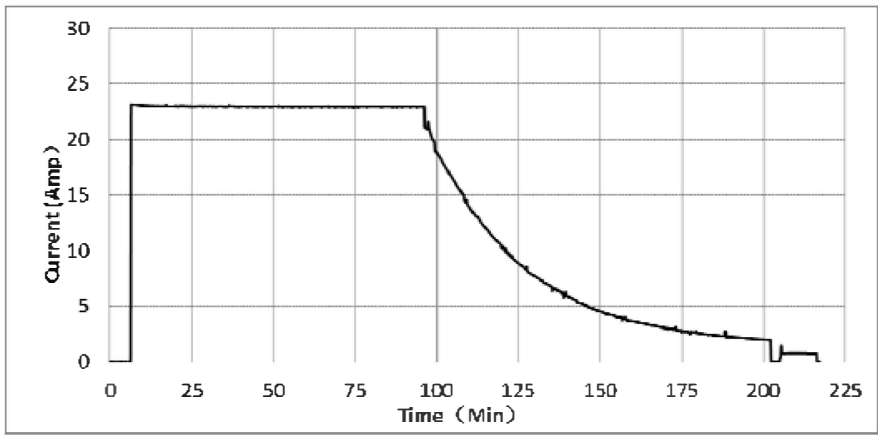

(b)

Fig. 6. Battery Three-Stage Charging Profile (a) Voltage, (b) Current

\section{Battery Self-Discharge}

After the battery is fully charged, the open circuit voltage reaches nearly $13.2 \mathrm{~V}$, a value that is used as the starting voltage in the manufacturer's data sheet shown in Fig. 1. In practice, however, this value drops quickly as soon as the battery is disconnected from the charger. More specifically, the voltage drops by $0.1 \mathrm{~V}$ within the first minute, then continues to drop at a slower rate before stabilizing.

To determine the correct open circuit voltage at full charge, the battery is allowed to rest overnight while monitoring its terminal voltage. Fig. 7 shows how the voltage drops from 13.2 $\mathrm{V}$ down to a steady value of $12.91 \mathrm{~V}$ during 13 hours of "rest". This phenomenon is believed to be due to the charges accumulated at the battery terminals during charging. 


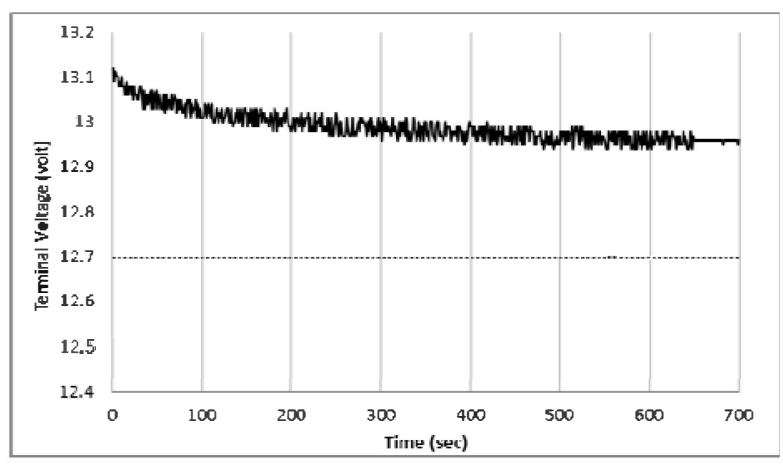

Fig. 7. Battery Overnight Self-Discharge.

\section{Battery Discharge Test at Constant Rate}

This step of the test is to check the accuracy of the static battery model that was derived from the manufacturer data in the previous section. The battery was tested under two discharge rates, namely 4-hour and 8-hour rate. The manufacturer data sheet indicates that the corresponding battery capacity for these rates is $72 \mathrm{Ah}$ and $79 \mathrm{Ah}$, respectively. Consequently, the respective values of current draw are $18.0 \mathrm{~A}$ and $9.9 \mathrm{~A}$. Fig. 8 shows the measured and calculated voltage curves for the 4-hour and 8-hour discharge rates. The graphs clearly show that the analytical model predicts battery performance with good accuracy.

\section{Derivation of DyNAMic BATTERy MODEl From LABORATORY TEST DATA}

A sudden change in load current is known to cause a sudden change in battery voltage, followed by an exponential decay or rise before settling to a steady value. A first-order circuit such as the one shown in Fig. 9 is often considered a sufficiently accurate dynamic battery model. Herein, a capacitor $C_{t}$ is added across a portion of the battery equivalent resistance $R_{s}$ (denoted by $R_{t}=k R_{s}$, where $0<\mathrm{k}<1$ ) to account for the exponential component of the transient response. The remaining portion of series resistance, denoted by $R_{s}{ }^{\prime}=(1-k)$ $R_{s}$, accounts for the instantaneous change in the voltage response. In addition, the size of the capacitor $C_{t}$ depends on whether the battery is under load or under no load. Let these capacitances be respectively denoted by $C_{t-o n}$ and $C_{t-o f f}$.

Starting from rest, if a constant load current $\mathrm{i}$ is suddenly drawn from the battery, the voltage drop experienced at the battery terminals is a simple sum of the voltage drop across Rs' and $\mathrm{Ct}$ :

$$
V_{d r o p}=(1-k) R_{s} i+k R_{s} i\left(1-e^{-t / \tau_{o n}}\right)
$$

Where $\tau_{o n}=k R_{s} C_{t-o n}$ is the time constant under load. If the load is disconnected from the battery at $t=t_{l}$, the voltage drop is reduced to

$$
V_{d r o p}=V_{t 1} e^{-t / \tau_{o f f}}
$$

Where $V_{t l}$ is the voltage across $C_{t}$ at the instant the load is switched off, and $\tau_{\text {off }}=(1-k) R_{s} C_{t-\text { off }}$ is the time constant under no load. The next subsection describes a simple battery test in an effort to determine the values of the equivalent circuit parameters in Fig. 9.

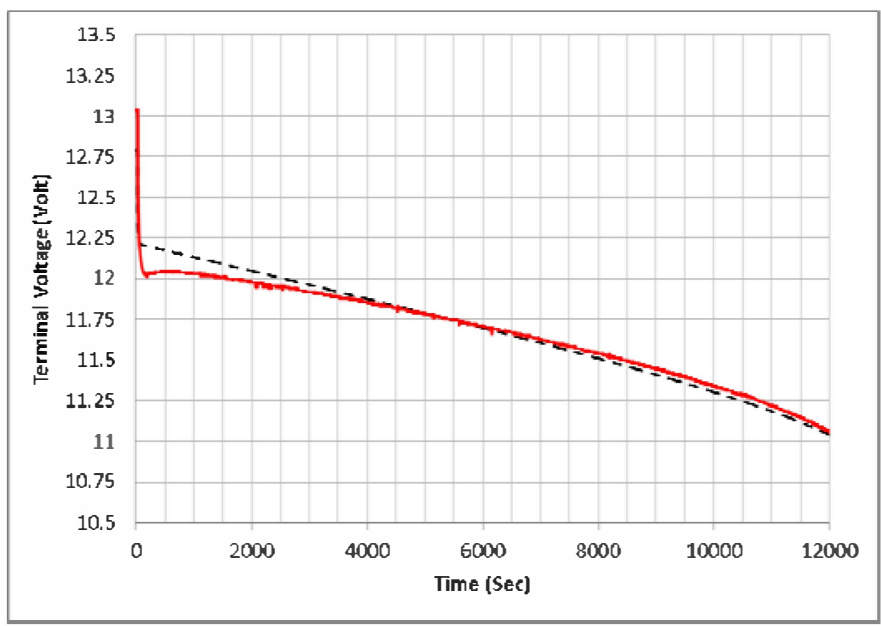

(a)

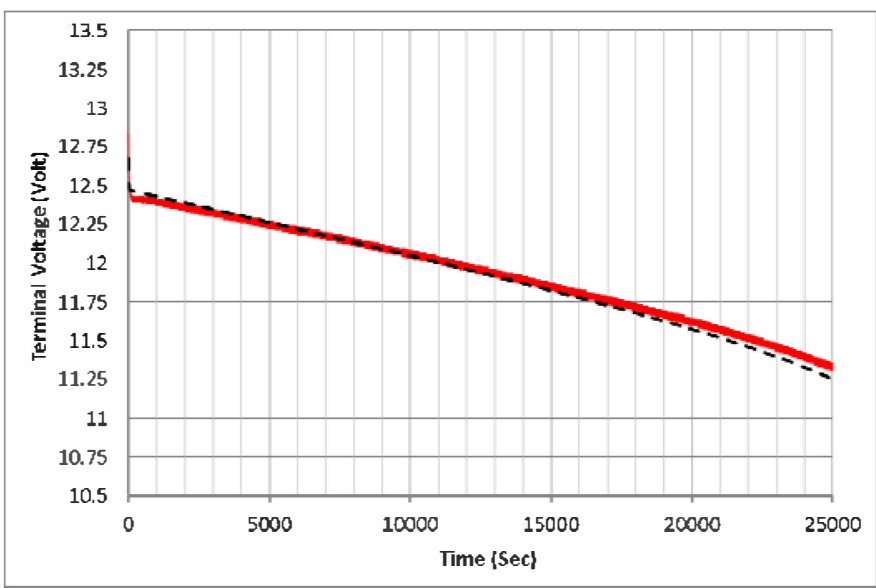

(b)

Fig. 8. Battery Discharge Curves, (a) 4-Hour Rate, (b) 8-Hour Rate. $\mathrm{R}_{1}$

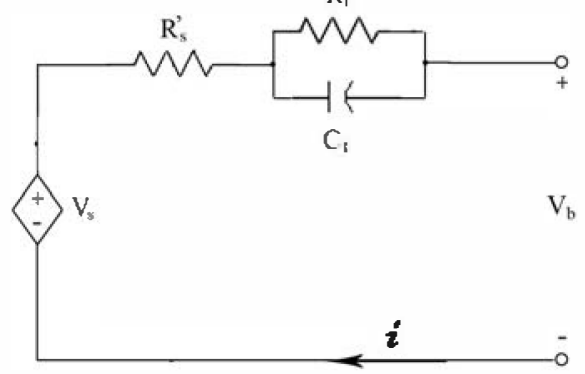

Fig. 9. Dynamic Battery Equivalent Circuit.

\section{A. Uniform Current Discharge}

To determine the dynamic circuit parameter values, shortterm pulse current discharges of $20 \mathrm{~A}, 15 \mathrm{~A}, 10 \mathrm{~A}$ and $5 \mathrm{~A}$ are applied to a fully charged battery and changes in its terminal voltage are recorded. Each pulse lasts nearly one minute seconds followed by a rest period of about two minutes. Fig. 10 below shows the current draw and corresponding battery voltage. The magnitude of the sudden voltage drop following the rise of each current pulse allows the calculation of (1- 
k)Rs, while the exponential voltage drop that follows the sudden drop allows the calculation of both kRs and the time constant $\tau$ on. Finally, the slow rise in voltage during the rest period provides information about the time constant $\tau$ off. The calculated values of these parameters for each current pulse are summarized in Table I. Note the total battery resistance for the lower current pulses (10 A and $5 \mathrm{~A}$ ) matches that in Fig. 3(a) more closely than for the higher current pluses. Another remark is that kRs averages nearly $35 \%$ of the total resistance. Finally, the calculated time constants indicate that the average values of Ct-on and Ct-off are 1,200 F an 7,200 F, respectively.

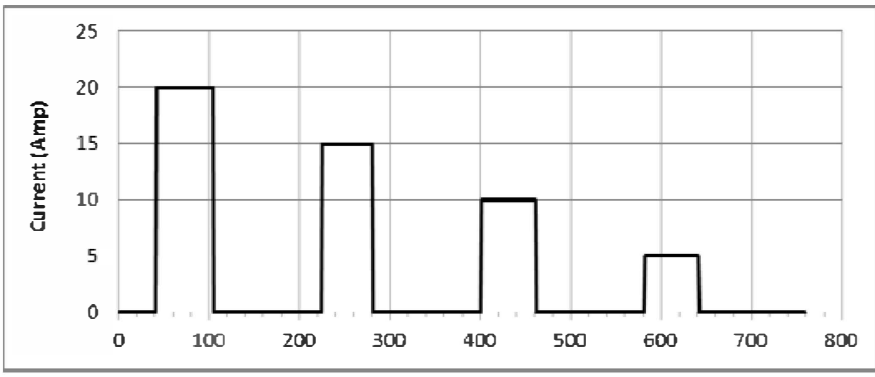

(a)

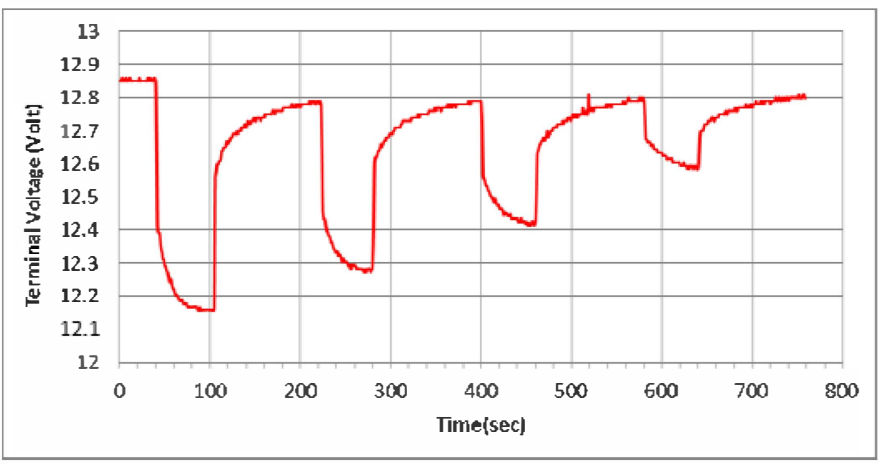

(b)

Fig. 10. Uniform Discharge, (a) Load Current, (b) Battery Voltage.

TABLE I

Calculated Dynamic Parameter Values.

\begin{tabular}{||c||c||c||c||c||}
\hline Current $(\mathrm{A})$ & 20 & 15 & 10 & 5 \\
\hline \hline$(1-k) R_{s}(\Omega)$ & 0.022 & 0.023 & 0.023 & 0.024 \\
\hline \hline$k R_{s}(\Omega)$ & 0.012 & 0.013 & 0.014 & 0.015 \\
\hline \hline$R_{s}(\Omega)$ & 0.033 & 0.036 & 0.037 & 0.039 \\
\hline \hline$\tau_{\text {on }}(\mathrm{sec})$ & 14 & 15 & 17 & 20 \\
\hline \hline$\tau_{\text {off }}(\mathrm{sec})$ & 96 & 98 & 100 & 101 \\
\hline
\end{tabular}

\section{B. Non-Uniform Current Discharge}

To evaluate the accuracy of the battery dynamic model described above, a number of test profiles covering a wide current range that is limited only by the power rating of the load bank have been conducted both experimentally and numerically under different levels of battery state-of-charge. A sample of these tests is shown in Fig. 11(a) below where the current is varied in incremental steps between 0 and $25 \mathrm{~A}$, and the corresponding measured and simulated battery terminal voltages are potted in Fig. 11(b). In this particular example, the initial battery voltage is $12.35 \mathrm{~V}$ which corresponds to $62 \%$ SOC [13]. The results indicate that the model developed predicts the battery performance under both steady-state and transient conditions with acceptable accuracy.

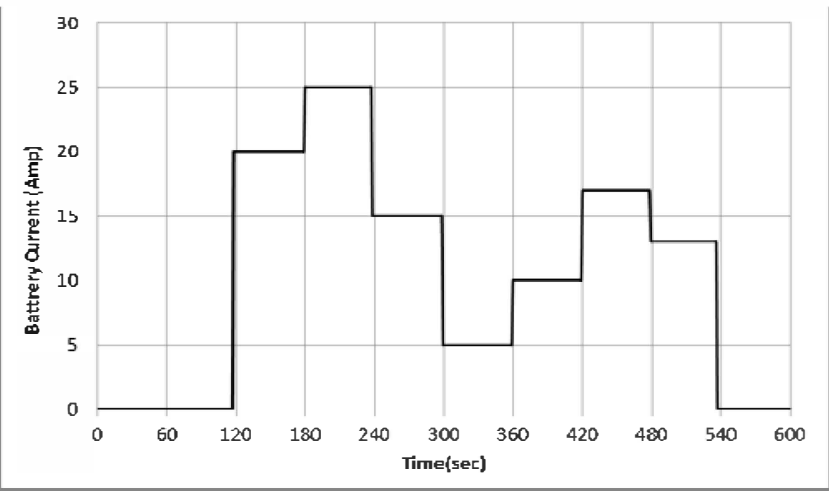

(a)

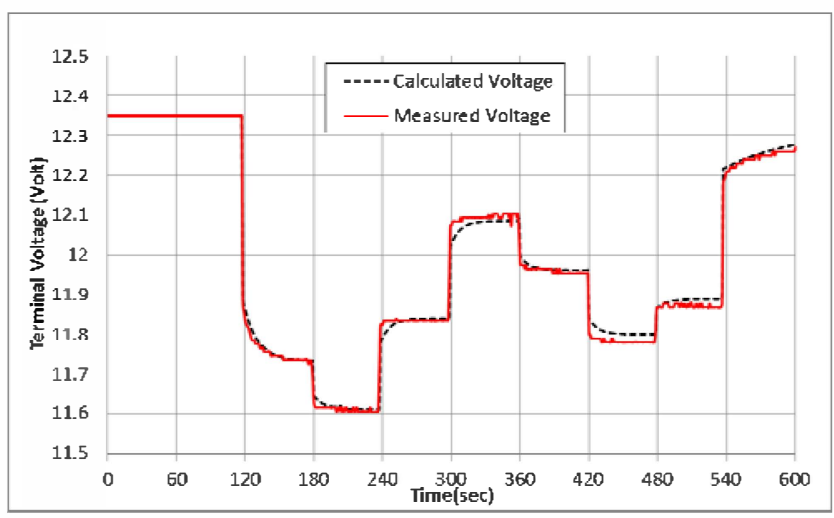

(b)

Fig. 11. Non-Uniform Discharge, (a) Load Current, (b) Battery Voltage.

\section{CONCLUSIONS}

In this paper, a circuit model for an AGM Lead-acid battery has been developed for both steady-state and transient conditions: The steady-state model which consists of two dependent circuit parameters was derived from the discharge curves provided by the manufacturer. The dynamic model is obtained by adding a capacitive element across a portion of the series resistance, and the parameter values are obtained from laboratory tests. The resulting circuit model is found to accurately predict battery performance under both constant as well as variable current discharge.

The tests in this study were conducted indoors at room temperature. Future work consists of upgrading the circuit model by taking into account battery temperature when operating outdoors.

\section{REFERENCES}

[1] Khadkikar, V.; Varma, R.K.; Seethapathy, R.; Grid Voltage Regulation Utilizing Storage Batteries in PV Solar - Wind Plant based Distributed Generation System, IEEE Elect. Power and Energy Conference, 2009.

[2] Mossoba, J.; Ilic, M.; Casey, L.; PV Plant Intermittency Mitigation Using Constant DC Voltage PV and EV Battery Storage, IEEE Conference on Innovative Technologies for an Efficient and Reliable Electricity Supply, 2010 , Page(s): 297 - 301 
[3] Thomas D. Hund, Sigifredo Gonzalez, and Keith Barrett, Grid-Tied PV System Energy Smoothing, 35th IEEE Photovoltaics Specialists Conference, 2010

[4] Wertz, J.A., and Clough, T.J, "Development of advanced lead acid batteries for electric vehicles - the use of additives to increase performance and extend life of AGM cells", $14^{\text {th }}$ Annual Battery Conference on Applications and Advances, 1999.

[5] Kong-Soon Ng, Chin-Sien Moo, Yi-Ping Chen, and Yao-Ching Hsieh, "State-of-Charge Estimation for Lead-Acid Batteries Based on Dynamic Open-Circuit Voltage", $2^{\text {nd }}$ IEEE Int. Conf. on Power and Energy, 2008.

[6] Min Chen and Gabriel A. Rincon-Mora, "Accurate Electrical Battery Model Capable of Predicting Runtime and I-V Performance", IEEE Transactions on Energy Conversion, Vol.21, No.2, June, 2006.

[7] Nosh K. Medora, Alexander Kusko, "An Enhanced Dynamic Battery Model of Lead-Acid Batteries Using Manufacturer's Data", $28^{\text {th }}$ IEEE Annual International Telecommunications energy Conference, 2006.

[8] Patrick J.B., Andre V., Will H. A., Paul P. J. van den Bosch, "Prediction of Battery Behavior Subject to High-Rate Partial State of Charge", IEEE Trans. on Vehicular Technology, Vol.58, No.2. Feb. 2009

[9] Olivier Tremblay, Louis-A. Dessaint, and Abdel-Illah Dekkiche, "A Generic Battery Model for the Dynamic Simulation of Hybrid Electric Vehicles", IEEE Vehicle Power and Propulsion Conference, 2007

[10] Xue Zhe.Wei, Xiao Peng.Zhao, Yong Jun.Yuan, "Study of Equivalent Circuit Model for Lead-acid Batteries in Electric Vehicle", Int. Conf. onMeasuring Technology and Mechatronics Automation, 2009.
[11] Robert Rynkiewicz,"Discharge and Charge Modeling of Lead Acid Batteries", $24^{\text {th }}$ Annual IEEE Applied Power Electronics Conference and Exposition, 2009

[12] R.Prieto, J.A.Oliver, I.Reglero and J.A.Cobos, "Generic Battery Model Based on a Parametric Implementation", $24^{\text {th }}$ Annual IEEE Applied Power Electronics Conference and Exposition, 2009.

[13] http://www.sunxtender.com/pdfs/Battery_Technical_Manual.pdf

\section{BIOGRAPHIES}

Wenxin Peng was born in Chongqing, China in 1986. He received his B.S degree in Applied Physics from Tongji University, Shanghai, China in 2009. $\mathrm{He}$ is currently a graduate student major in Electrical Engineering of University of Nevada, Las Vegas to pursue his M.S. degree. He is a student member of Institute of Electrical and Electronics Engineers (IEEE) and his interests are in energy storage systems, power systems and renewable energy.

Yahia Baghzouz was born in Beni-Amrane, Algeria in 1956. He received his B.S., M.S. and Ph.D. degrees in electrical engineering from Louisiana State University, Baton Rouge, LA, in 1981, 1982 and 1986, respectively. $\mathrm{He}$ is currently professor of Electrical Engineering, and Associate Director of the Center for Energy Research at the University of Nevada, Las Vegas. His interests are in power quality, power conversion and renewable energy. He is a registered Professional Engineer in the State of Nevada, and Senior Member of the Institute of Electrical and Electronics Engineers (IEEE) 